\title{
MIDAS
}

Museus e estudos interdisciplinares

$3 \mid 2014$

Varia e dossier temático: "Museos y participación biográfica"

\section{Juan Carlos Rico, ed. - Museos del Templo al Laboratorio: La Investigación Teórica}

\section{Alexandre Matos}

\section{OpenEdition}

\section{Journals}

Edição electrónica

URL: http://journals.openedition.org/midas/422

DOI: $10.4000 /$ midas. 422

ISSN: 2182-9543

\section{Editora:}

Alice Semedo, Paulo Simões Rodrigues, Pedro Casaleiro, Raquel Henriques da Silva, Ana Carvalho

\section{Refêrencia eletrónica}

Alexandre Matos, "Juan Carlos Rico, ed. - Museos del Templo al Laboratorio: La Investigación Teórica », MIDAS [Online], 3 | 2014, posto online no dia 01 junho 2014, consultado no dia 22 setembro 2020. URL : http://journals.openedition.org/midas/422 ; DOI : https://doi.org/10.4000/midas.422

\section{Este documento foi criado de forma automática no dia 22 setembro 2020.}

\section{c) (1) (ㅇ)}

Midas is licensed under a Creative Commons Attribution-NonCommercial-ShareAlike 3.0 International License 


\title{
Juan Carlos Rico, ed. - Museos del Templo al Laboratorio: La Investigación Teórica
}

\author{
Alexandre Matos
}

\section{REFERÊNCIA}

Carlos Rico, Juan, ed. 2011 - Museos del Templo al Laboratorio: La Investigación Teórica.

Madrid: Sílex Ediciones. 343 páginas, ISBN: 978-84-7737-453-4.

1 Pensar 25 anos de investigação científica é um trabalho corajoso que deve ser sempre reconhecido pela comunidade científica e incentivado, se não pela consciência dos seus responsáveis, pelas universidades e centros de investigação. É corajoso em qualquer área científica, mas permitam-nos o arrojo de o considerar um pouco mais numa área como a museologia e, especificamente, nas questões relacionadas com o processo expositivo, entendido no seu todo, pensando em conteúdo, contentor, produtores e consumidores e as relações (ou ausência de) entre cada um destes elos.

2 Juan Carlos Rico, editor e autor principal deste importante trabalho de investigação, publica neste primeiro livro de uma obra que pretende refletir sobre 25 anos de investigação museográfica (a qual terá mais quatro volumes dedicados à docência, experimentação prática, ao espaço e sua perceção nas suas diferentes valências e um final com reflexões pessoais do autor) as inquietações, dúvidas, questões, metodologias, caminhos, recuos, respostas, sucessos e insucessos que presidiram ou resultaram do esforço de um quarto de século, centrado na sua pessoa, mas partilhado por colegas, alunos, profissionais de museus e instituições que permitiram, conforme o próprio autor indica, a sua realização.

3 Este primeiro livro aborda a investigação como passo primeiro e fundamental para a realização de qualquer trabalho que pretenda inovar e encontrar novas ferramentas, mais simples e eficientes, para cumprir o propósito a que se destina. No caso, o objeto 
de reflexão é a museografia e o livro aborda as reflexões e ideias, avanços e recuos gerados pelo processo de investigação, divididos em cinco capítulos e antecedidos de uma introdução, onde se enuncia o propósito deste e dos restantes livros previstos na obra, enquadrando-os nas distintas fases do projeto expositivo de forma comparativa. Inclui ainda uma breve nota introdutória à investigação teórica onde Juan Carlos Rico nos apresenta, sumariamente, a estrutura do trabalho de investigação desenvolvido no período cronológico referido, e como consequência, a estrutura da presente publicação.

O primeiro desses capítulos dedica-se inteiramente à primeira fase de investigação, decorrida nos primeiros oito anos do processo (1986-1994), nos quais o autor se dedica ao estudo e análise das relações existentes entre conteúdo e contentor, ou seja, entre edifício e coleção, arquitetura e objeto, dos diálogos existentes entre estes dois vetores e as influências externas trazidas pela técnica e pelos diferentes profissionais que intervêm nessa relação. Um processo moroso, como se poderá constatar, mas que é próprio da fase inicial de qualquer investigação. Determinar o objeto de estudo para saber, quais as questões e âmbito que poderão ser levantados durante o processo é, segundo se depreende da explanação do autor, tão crucial como qualquer bom alicerce nas fundações de um edifício.

5 No segundo, relativo à fase de investigação decorrida entre 1995 e 1997, na qual as dúvidas sobre os vários caminhos a seguir, resultantes do primeiro período do trabalho, levaram à formulação da questão: Porque não vêm aos museus? e à consequente análise, estruturada em quatro estados (inicial, intencional, realidade e final), que pretende responder, do ponto de vista dos profissionais e visitantes à questão enunciada, através de um método que nos parece, ao contrário até do que o autor afirma, terá rigor científico suficiente para responder, em parte pelo menos, à importante questão através de entrevistas estruturadas, consultas aos profissionais e observação do comportamento dos visitantes. Este período e os resultados daí advindos sustentam a procura de um modelo (ou mais) de museu/exposição mais consentâneo com a realidade atual. Essa procura é descrita no capítulo terceiro «Hacia un nuevo prototipo?» onde se descreve o período que vai de 1998 a 2006.

6 A procura desse protótipo é influenciada por diversos fatores externos como as mudanças sociais e tecnológicas ocorridas que juntamente com o desenvolvimento verificado na museologia e ciências conexas, nos seus profissionais e nas relações com as expectativas do público levam à criação do modelo La Caja de Cristal. Um modelo de museu organizado em duas grandes áreas: Centro de Comunicação (exposições, reservas visitáveis, ateliers, auditório) e Centro de Investigação Integrada (que assegura a documentação, investigação teórica, prática e técnica e o setor de educação) às quais se junta a área de trabalho para a coordenação, investigação e questões técnicas, divididas em três âmbitos individuais, interligados entre si, que são o público, o técnico e a direção ou coordenação. Este modelo, assente num museu transparente, aberto ao exterior é testado, com o auxílio de escolas de arquitetura de diferentes países, tendo em conta os fatores atrás enunciados, naquela que o autor apelida de fase mais produtiva do processo até ao momento.

7 De forma contínua a investigação chega a uma fase em que se abre a outros conhecimentos técnicos e científicos porque o objeto de estudo se alarga e passa a incluir a paisagem, a cidade, o património cultural e o autor reflete sobre a sua relação com o processo expositivo, construindo uma narrativa muito interessante que nos leva desde o campo, à cidade, ao centro histórico, ao monumento, ao museu, à galeria ou 
feira de arte até à sala de casa e ao acesso virtual pré e pós contacto direto com o objeto cultural. No final dessa narrativa, na qual se percebe ainda mais a importância dos contributos de outras áreas científicas e técnicas para este momento da investigação, Juan Carlos Rico apresenta, resumidamente, as reflexões dele e de duas colegas, que nos recordam a importância de discussões informais e de diferentes perspetivas nos processos de investigação. A este capítulo, decorrido entre 2006 e 2008, o autor dá o título «Un Cambio de Escala: Mucho Más en Mucho Menos» como reflexo acertado dos diversos contributos e dados que chegam, entretanto, ao processo e das poucas possibilidades da sua exploração que os recursos ao dispor do autor permitem.

O quinto e último capítulo sobre os 25 anos de processo de investigação, refere-se ao ano de 2009 e apresenta o museu, num sentido figurado, como um laboratório. Isto é, um local que permite uma observação pormenorizada dos fenómenos resultantes da definição dos três componentes analisados (contentor, conteúdo e público), aplicação dos modelos e das técnicas expositivas, nunca descurando a presença do visitante (peça fundamental na investigação de Rico), ou seja, o momento crítico de analisar o processo expositivo desde o ponto de vista concreto do espaço, do objeto e do visitante ou observador, tendo em conta os resultados alcançados nas primeiras fases da investigação, como tão bem se ilustra esquematicamente (p.190). Esse esquema permite-nos percecionar com clareza todo o percurso da investigação, o qual começa por abordar questões centrais aos objetos de estudo e depois refina, de forma clara, o(s) seu(s) âmbito(s) na resposta à questão primordial da investigação que só estará concluída com a publicação dos restantes livros sobre estas últimas décadas de investigação sobre museografia. A finalizar este último capítulo e antes de dar a palavra a outros autores que contribuíram para este processo, o autor apresenta, em forma de sugestão, um conjunto de reflexões pessoais sobre a investigação que são de salutar dada a experiência acumulada e agora partilhada.

Uma nota importante na caraterização da estrutura deste livro é a constante preocupação do autor com a descrição de forma mais ou menos extensa, conforme os casos, da metodologia utilizada em cada um dos capítulos. Este rigor com a metodologia, para além dos benefícios que Juan Carlos Rico descreve ter trazido para o processo, a identificação dos insucessos e o consequente retorno, por exemplo, permitirá também a outros investigadores a sua utilização ou recusa de forma mais fundamentada.

Por fim, uma segunda parte do trabalho, intitulada «Con Todos», abre a porta da narrativa do processo de investigação a alguns dos muitos investigadores (incluindo portugueses), universidades e outras instituições que, ao longo dos 25 anos descritos, contribuíram ou fizeram parte do seu desenvolvimento. Historiadores, arquitetos, designers, artistas e arqueólogos que trabalham a museografia do ponto de vista teórico, prático, com ou sem ligações institucionais, representado diferentes interesses, convergem na procura de soluções para um problema comum: a apresentação pública do património cultural de forma eficiente e cumprindo os requisitos qualitativos que norteiam o museu atual em termos de investigação, conservação, educação e fruição.

11 Este livro é não só recomendável, como também obrigatório para os interessados na museografia e nos processos científicos que a sustentam. Constitui um manual técnico, em certa medida, onde os museólogos e responsáveis por museus podem absorver conceitos sobre o que precisamos de respeitar para expor o património cultural. A descrição dos 25 anos de um processo de investigação, tal como afirmamos acima, é um 
contributo que não pode ser esquecido, muito menos quando esse contributo é fundamental no panorama científico internacional.

\section{AUTORES}

\section{ALEXANDRE MATOS}

Universidade do Porto, Faculdade de Letras, Departamento de Ciências e Técnicas do Património, Portugal, ammatos@letras.up.pt 